\title{
Commentary
}

\section{A Positive Impact Rating for Business Schools: Case Study}

\author{
Thomas Dyllick $1,2, *(\mathbb{D})$ and Katrin Muff ${ }^{1,3}$ \\ 1 The Institute for Business Sustainability, 6005 Lucerne, Switzerland; Katrin.Muff@gmail.com \\ 2 Institute for Economy and the Environment, University of St. Gallen, 9000 St. Gallen, Switzerland \\ 3 LUISS Business School, LUISS Guido Carli University, 00162 Rome, Italy \\ * Correspondence: Thomas.Dyllick@unisg.ch
}

Received: 28 September 2020; Accepted: 9 November 2020; Published: 17 November 2020

\begin{abstract}
Business school rankings have been criticized, to blindly "follow the money" with their strong focus on salaries and economic performance, thereby reflecting the values and expectations of the times the rankings were created. Rankings are increasingly seen as out of touch with changing demands on business and business schools to address issues of social impact and sustainability. The newly created Positive Impact Rating for Business Schools (PIR) provides an answer to these demands. This paper presents a case study on the new PIR. It first provides an overview of the critique of current business school rankings. It highlights emerging trends towards including social impact and sustainability in the business school landscape, with a focus on the UN Sustainable Development Goals, research initiatives, accreditations, and rankings. It then presents and discusses in detail the new PIR launched in January 2020 at the WEF in Davos and its initial reception. This new "by students and for students" rating reaches out to students to assess their own business schools on how they perceive them in creating a positive impact on and for the world.
\end{abstract}

Keywords: business school ranking; business school accreditation; sustainability; social impact; UN sustainable development goals; purpose orientation; student organizations

\section{Introduction: Critique of Current Rankings}

Business School rankings have been criticized for many years [1-4]. They largely "follow the money" [5] and reflect the values and expectations of the times when the rankings were created. The Financial Times MBA ranking started in 1999, the Economist followed suit in 2002. Both rankings show a strong focus on salaries and economic performance. Much less emphasis is placed on what is taught and learned at schools. The role an MBA plays in the students' lives is, however, much larger. It is often a life-changing experience for the students, shaping their personal development and further directions in their careers, with salary being at best a partial and often misleading indicator.

The criticism of rankings ranges from the data collection methods to the measures used and the validity of the results of the rankings. A 2018 survey run by the Association of MBAs among international business school stakeholders seriously questions the effectiveness of MBA rankings [6]. The survey reports lack of trust in the data collection methods, because self-reporting of evidence by schools leads to distorted results. When asked about their preferred method for data collection, the respondents point to a student survey to produce authentic feedback on program performance. The ranking criteria are criticized for their narrowness along with a lack of transparency about the criteria selection process. In particular, the over-reliance on salary metrics in current rankings does not necessarily reflect what students seek and expect from their MBA. Rankings are seen to be increasingly out of touch with the delivery of the programs and the changing expectations of the students on the ground. Overall, while there is serious doubt if the rankings adequately reflect the performance of 
the schools, there is agreement that rankings have a significant influence on the demand for MBA programs. This shows in the fact that rankings have become an important aspect of the schools' brands and business models.

There are numerous business school rankings, that are mostly organized and published by business publications. The most influential rankings in Europe are, according to a ranking of rankings, the Financial Times (FT) and the Economist (ECON). In the USA, U.S. News comes in ahead of FT and Business Week ahead of the Economist [7]. Both leading European rankings, FT and ECON, use quite similar ranking criteria, focusing heavily on salary and placement opportunities as can be seen from Table 1.

Table 1. Weightings of Financial Times (FT) and Economist (ECON) MBA and Masters in Management (MIM) rankings.

\begin{tabular}{|c|c|c|c|c|}
\hline Categories and Criteria & FT MBA 2019 & FT MIM 2019 & ECON MBA-2019 & ECON MIM 2019 \\
\hline Salary and Placement Total & $57 \%$ & $55 \%$ & $68 \%$ & $69 \%$ \\
\hline Salary & $20 \%$ & $20 \%$ & & $23 \%$ \\
\hline Salary increase & $20 \%$ & $10 \%$ & $20 \%$ & \\
\hline Salary before entering school & & & $3 \%$ & \\
\hline Value for money & $3 \%$ & $5 \%$ & & \\
\hline Career progress & $3 \%$ & $5 \%$ & & \\
\hline Aims achieved & $3 \%$ & $5 \%$ & & \\
\hline Careers service & $3 \%$ & $5 \%$ & $12 \%$ & $12 \%$ \\
\hline Employed at 3 months & $2 \%$ & $5 \%$ & $12 \%$ & $12 \%$ \\
\hline Alumni recommend & $3 \%$ & - & & \\
\hline Diversity of recruiters & & & $11 \%$ & $12 \%$ \\
\hline Potential to network & & & $10 \%$ & $10 \%$ \\
\hline Faculty and Research Total & $21 \%$ & $16 \%$ & $9 \%$ & $10 \%$ \\
\hline FT research rank & $10 \%$ & - & & \\
\hline Faculty with doctorates & $5 \%$ & $6 \%$ & $3 \%$ & $3 \%$ \\
\hline International faculty & $4 \%$ & $5 \%$ & & \\
\hline Female faculty & $2 \%$ & $5 \%$ & & \\
\hline Faculty/student ratio & & & $3 \%$ & $3 \%$ \\
\hline Student faculty rating & & & $3 \%$ & $3 \%$ \\
\hline International Experience and Diversity Total & $18 \%$ & $29 \%$ & $13 \%$ & $15 \%$ \\
\hline International student mobility & $6 \%$ & $8 \%$ & & \\
\hline International course experience & $3 \%$ & $8 \%$ & $2 \%$ & $2.5 \%$ \\
\hline Languages required/offered & $1 \%$ & $1 \%$ & $2 \%$ & $2.5 \%$ \\
\hline International students & $4 \%$ & $5 \%$ & $6 \%$ & $7 \%$ \\
\hline Female students & $2 \%$ & $5 \%$ & $3 \%$ & $3 \%$ \\
\hline International board & $2 \%$ & $1 \%$ & & \\
\hline Women on board & & $1 \%$ & & \\
\hline Student and Educational Quality Total & $3 \%$ & & $10 \%$ & $5 \%$ \\
\hline Student GMAT score & & & $3.5 \%$ & \\
\hline Prior work experience & & & $2.5 \%$ & \\
\hline Student program rating & & & $2 \%$ & $2.5 \%$ \\
\hline Student facility rating & & & $2 \%$ & $2.5 \%$ \\
\hline CSR and sustainability courses & $3 \%$ & & & \\
\hline
\end{tabular}

The categories are created by the authors of this paper for the purpose of comparing the different rankings. Weightings are taken from FT and ECON; categories-in bold-and totals are from the authors. Rounding differencesare possible.

There are four different categories of criteria in the 2019 MBA and Masters in Management (MiM) rankings of FT and ECON: salary and placement, faculty and research, international experience and diversity, student and educational quality. Their relative weights vary greatly. Salary and placement criteria, however, are by far the most important category in all four rankings. Their weights vary between 55\% (FT MIM) and 69\% (ECON MIM), with the FT weightings around 55\% and the ECON weightings clearly higher with more than two thirds of the total weighting. Faculty and research weightings lie between $9 \%$ for the ECON MBA and $21 \%$ for the FT MBA. They are clearly more relevant for the FT (16-21\%) than for the ECON (9-10\%) rankings. While the FT perspective values faculty research and qualifications as such very high, the ECON perspective is more interested in the faculty value for the students. International experience and diversity criteria vary between $13 \%$ (ECON MBA) and 29\% (FT MIM), with the FT values being clearly higher (18-29\%) than the ECON values (13-15\%). 
Student and educational quality criteria are almost exclusively used by ECON (5-10\%), while FT has only recently introduced a criterion for corporate social responsibility courses in MBA rankings.

It can hardly be overlooked that both FT and ECON rankings reduce the student perspective to expectations regarding salary and placement. Learning and education, the learning process, learning environment and learning results are not seen to be of much relevance for students, despite of them spending several formative years of their lives at business schools. A business school education thereby is reduced to one instrumental function, to provide easy access to highly paid jobs. Learning for life, personal development in a diverse environment, learning of social skills and educating responsible citizens and leaders may happen, but they do not count for rankings. So why should the business schools take them into consideration? Moreover, why should then society-in the case of public schools-pay for a business school education? However, not only learning and education are disregarded in these rankings, students are also not asked to express their expectations or to assess the educational quality of their programs and their school's engagement. ECON uses at least some student evaluations-for program rating, facility rating, and faculty rating - while FT does not use them at all. Regarding faculty quality, the two rankings look mostly at a few formal elements such as the number of faculty with a doctorate, the student-faculty ratio, and their publications. Crucial elements of teaching and learning effectiveness, however, such as practical experience, pedagogical qualifications, or interpersonal skills of the faculty, however, are not touched upon. One may also wonder, why FT did not introduce their new criterion for corporate social responsibility courses in their MIM ranking as well.

Recently, voices have been getting louder suggesting that business schools and business school rankings may be out of touch with changing societal conditions of business and demands in the fields of ethics, responsibility, and sustainability. In 1970 Milton Friedman famously argued that "the business of business is business" [8]. Yet, the business world had to learn over the past twenty years that the business of business is more than business. Business schools, however, have turned a blind eye on the fact that they have been focusing more and more on business as well, strongly supported by business school rankings [9]. Paul Polman, former CEO of Unilever and Board Chair of the Said Business School at Oxford is very explicit in his critique of business schools: "We have created a monster with the MBA that should not exist", warning that it has "a narrow definition of success" that will become "obsolete" in one or two years. André Hoffmann, Vice-President and majority shareholder of Roche, backer of the Hoffmann Global Institute for Business and Society at INSEAD adds: "We need to create a new breed of leader. Short-term profit maximization is not the way to run a complex environment" [10].

Looking at the values behind business school rankings, they mirror a vision of business schools and their educational purpose much in line with Friedman's position. The dominant rankings measure to what extent the schools provide income and market value to their graduates [5]. They also create reputational and marketing value for the schools, which allows them to be more attractive for well-qualified international students and for highly paid research-active faculty. Rankings have a profound influence on schools in terms of hiring and promotion decisions, curricular changes, selection among prospective applicants and much more [4]. Ranking management has long become a new management function for business schools, with a focus on the school's rankings participation and results. While this includes sometimes useful changes in program development, it often includes phony changes in the spirit of "gaming" the rankings system.

In the past decade, the rankings' narrow and singular focus on economic success and individual advantages has been met with increasing criticism from business, but also from within schools and students [1]. There have been interesting innovations in the business school landscape embracing social impact and sustainability. We will look at the overarching role of the UN Sustainable Development Goals, at initiatives focusing on research, accreditations, and rankings. Then we will present and discuss a completely new and innovative rating with an explicit focus on the positive impact of business schools that effectively addresses the critique described so far. 


\section{Social Impact and Sustainability as Emerging Topics in the Business School Landscape}

Over the last quarter century, business schools have been the major success story in the world of higher education, at least when measured in terms of growing demand. However, business schools have been heavily criticized for having become successively the objects of a "tyranny of the faculty" and a "tyranny of the markets" at the expense of a professional orientation and a contribution to society $[9,11,12]$. Today, there are growing societal pressures for business to take the lead in finding solutions to big societal problems such as the climate crisis, resource shortages, migration, and poverty. As this pressure mounts, Peter Tufano [13], Dean at the University of Oxford's Said Business School, acknowledges that "the traditional business school model is looking dated. The pace of change in business schools is far slower than in business, with the result that MBAs are increasingly less well prepared for the complex challenges of leading companies." To keep their relevance and remain a "force for good" for the next decades, business schools need to orient their teaching and research accordingly. While business schools have been rather slow in picking up these topics, there have been interesting developments in the business school landscape, with important institutional developments in the fields of research, accreditations, and rankings. These have in many ways been driven by developments on the level of the United Nations and are outlined below.

\subsection{The Overarching Role of the United Nations}

The United Nations certainly play an important role in influencing and changing the institutional environment of business and business schools alike. The UN Sustainable Development Goals (SDGs) and their Global Agenda 2030 were adopted by the global community in 2015, following the UN Millennium Development Goals which had been launched in 2000. The SDGs bring together governments, businesses, media, institutions of higher education, and local NGOs to improve the lives of the people in their country by the year 2030. But there have been numerous institutional developments long before.

The UN Principles for Responsible Management Education (PRME) were initiated in 2007 by UN Secretary-General Ban Ki-Moon as a platform to raise the profile of sustainability in business schools around the world. As a voluntary initiative with over 750 signatories across 90 countries in 2019, PRME calls on business schools all over the world to engage their education, research, and outreach activities to advance social responsibility and sustainability. While PRME traditionally based their approach on universal values in the areas of human rights, labor rights, the environment, and anti-corruption, more recently they have started to focus on the UN SDGs.

\subsection{Integrating Social Impact and Sustainability into Research}

Two outstanding initiatives need to be mentioned, which have contributed greatly to integrate social impact and sustainability into management research. The Canadian Network for Business Sustainability (NBS) was founded in 2005. It is a network of some 7500 researchers, students, and managers under the engaged leadership of Tima Bansal. It is dedicated to sharing research insights, making research more practically relevant and making business more sustainable. Its Sustainability Centers Community includes more than 150 business school members from around the world [14].

The Network for Responsible Research in Business and Management (RRBM) was founded in 2014 by a group of 24 leading scholars in 5 disciplines at 23 university-based business schools in 10 countries. It is led by visionary former president of the Academy of Management Anne Tsui and has meanwhile been joined by a much larger community. It developed a bold "Vision 2030" of business schools and scholars worldwide who have successfully transformed their research toward responsible science, producing credible knowledge that is ultimately useful for addressing problems important to business and society. Beyond publishing a position paper, RRBM has been engaged in promoting responsible research through naming pioneering schools and guest-editing journal special issues, organizing research summits, presentations, and awards [15]. While the NBS provides 
support for researchers and practitioners in the sustainability field, RRBM is dedicated to inspiring, encouraging, and supporting responsible research among business and management scholars.

\subsection{Integrating Social Impact and Sustainability into Accreditations}

Looking at international accreditations, topics such as ethics, sustainability, and social impact have made their way into the standards of the European Quality Improvement System (EQUIS) and the US-based Association to Advance Collegiate Schools of Business (AACSB) in recent years. In 2013, EQUIS revised its accreditation standards and established criteria for integrating ethics, responsibility, and sustainability (ERS) transversally into business school management. The new standards demand that ethical, responsible, and sustainable behavior are made an integral part of business schools' strategy and governance, as well as being reflected in their regular research, teaching, continuing education, and service activities. The full integration of ERS into all accreditation standards as early as 2013 has been an important signal to the business school world, even when it is left to the schools to clarify their understanding of ERS and report on the scope of their engagement [16].

In their "2020 Standards for Business Accreditation" AACSB made a significant leap by integrating two "guiding principles and expectations" covering ethics and societal impact into the new accreditation standards. In the principle on "ethics and integrity" it is stated that "the school encourages and supports ethical behavior and integrity by students, faculty, administrators, and staff in all its activities." Additionally, the new Standards present the expectation for all accredited schools to demonstrate their "societal impact" [17]. Both guiding principles should be reflected across all core elements of the standards, from the school's mission and strategic plan, to its curriculum and intellectual contributions, covering issues of policy as well as practice. In addition, a new standard No. 9 addresses directly and explicitly the topic of engagement and societal impact: "The school demonstrates positive societal impact through internal and external initiatives and/or activities, consistent with the school's mission, strategies, and expected outcomes" [17].

While EQUIS pioneered the integration of ERS in 2013, AACSB has been following suit in the 2020 revision of their standards for business accreditation. Now both global accreditation standards for business schools demand a full integration of ERS (EQUIS) or social impact (AACSB) into all core elements of their standards. This creates helpful pressure for business schools to rethink their positions and contributions to social impact and sustainability.

\subsection{Integrating Social Impact and Sustainability into Rankings}

The Aspen Institute's Business \& Society Program started to publish "Beyond Grey Pinstripes" in 2001, a biennial research survey and alternative ranking of business schools and continued to do so until 2011. They stopped the ranking because it was considered as too burdensome to run and of low validity. Beyond Grey Pinstripes highlighted innovative full-time MBA programs leading the way in the integration of issues concerning social and environmental stewardship into the curriculum.

Looking at the major European rankings, we do not yet see significant interest in social impact and sustainability. FT recently introduced a new criterion for Corporate Social Responsibility in their MBA ranking, however, with a negligible weight of 3\%. Both leading rankings, FT and ECON, express their interest in integrating aspects of responsibility and sustainability into their rankings, but are still unsure of how to do this in a way that is compatible with their existing rankings. There are, however, two rankings which are addressing the social impact or sustainability of business programs or universities: the Canadian Corporate Knights (CK) Better World MBA Ranking (BWR) [18] and the Times Higher Education (THE) University Impact Ranking (UIR). It is worth looking at them in more detail.

The BWR has been published since 2003 and its focus is on full-time MBA programs. Business schools offering the program were evaluated in 2019 on five performance indicators, with different weightings. It has a heavy research focus making up $60 \%$ of the weight. It looks at research intensity $(30 \%)$ and citation intensity $(20 \%)$ of publications in peer-reviewed academic journals considered to be part of sustainable development. The research focus is further strengthened 
by looking at the number of research institutes and centers dedicated to sustainable development issues $(10 \%)$. The educational side is covered by two criteria: the proportion of mandatory core courses on sustainable development topics in the MBA (30\%) and the proportion of women and minority racial groups among faculty count for $5 \%$ each. Both indicators are input assessments and do not say anything about the educational quality of the output or its impact. Although CK ranks MBA programs, four out of five indicators used and $70 \%$ of the total weightings have a focus on the whole school.

The Times Higher Education University Impact Ranking (UIR) [19] was launched in 2019. Its intention is to show how the global higher education sector is working towards the UN Sustainable Development Goals (SDGs). The ranking addresses not business schools but universities. Its focus is on impact on society, not just on research and teaching performance. Hence, the ranking intends a shift from input and process measures, used in most other rankings, to output and impact measures. In 2019, UIR collected data on 11 of the 17 SDGs from participating universities, leaving it to the universities to pick at least three SDGs on which to provide data. For 2020, they are expanding this to all 17 SDGs. In addition, all participating universities need to provide data on SDG 17 (partnerships for the goals). Times Higher Education provides specific sets of metrics for each SDG. Research metrics play an important role (mostly $27 \%$ of the weightings). They also look at "continuous metrics", which measure contributions to SDG impact, for example the number of graduates in relevant fields. They also ask for evidence to support their claims.

In summary, while the major European business school rankings-FT and ECON—are still hesitant to face the demands for social impact and sustainability, other rankings are addressing the challenge and move ahead. The Corporate Knights MBA ranking has been well received in the US, the UK and Canada. It has a strong research focus. The Times Higher Education impact ranking is a first global attempt to document universities' impact on society, rather than school or student performance. With a focus on the SDGs, there is a timely link to the goals of the global agenda. Yet, it is addressing universities, not business schools. Moreover, the UIR does not address the question of how the leadership skills and mindsets can be developed that will be needed to drive the change and transformation required in organizations to contribute effectively to the SDGs.

We can see from these numerous institutional developments that social impact and sustainability have become an increasingly important topic in the business school landscape. These topics have started to work their way into research institutions, accreditations, and rankings. Consequently, business schools are increasingly pressured to consider social impact and sustainability in their teaching, research, and outreach activities. The new Positive Impact Rating was created to support this development and to help speed up the needed transformation.

\section{The New Positive Impact Rating for Business Schools}

The new Positive Impact Rating for Business Schools (PIR) [20] builds on these multiplying demands to integrate social impact and sustainability in their activities. It was created to strengthen and accelerate these developments within business schools and to provide a more relevant selection tool for future students. Many students care deeply about making a positive difference through their professional lives, yet they do not necessarily know how to find the right business school to get prepared. The PIR is a tool for this next generation of change agents and a response to wide-spread demands for a positive impact of business schools.

The PIR is a new rating conducted by students and for students. Students around the world assess their business schools on how they perceive their positive impact. In its first edition, the 2020 edition, it has reached 2500 students. The PIR concept was developed in a multi-step prototyping process by a large group of committed and engaged academics, students, and business school stakeholders from many different countries. The PIR is organized as an independent, not-for-profit Association under Swiss law. It has been formally endorsed by WWF Switzerland, representing the environmental dimension, OXFAM International, representing the social dimension, and UN Global Compact Switzerland, representing the economic dimension. It is set up to be led by student organizations 
active in the responsibility and sustainability space. There is a formal collaboration with international student organizations oikos International, Net Impact, and AIESEC, but also with national student organizations like SOS (Students Organising for Sustainability; in the UK) and Studenten voor Morgen (in The Netherlands).

The results of the first edition of the PIR, the PIR 2020, were launched at the World Economic Forum in Davos, Switzerland, in January 2020 [21,22]. In many ways it was a pilot run for the new rating, with the new approach being tested. We now present and discuss the concept and some results of the PIR 2020 in detail by following five guiding questions (Table 2):

Table 2. Guiding questions and answers for presenting and discussing the Positive Impact Rating for Business Schools (PIR).

\begin{tabular}{ccc}
\hline & Guiding Questions & Answers \\
\hline 1 & What is the role of business schools? & A positive impact model for assessing \\
2 & Who conducts the assessment? & A rating by students and for students \\
3 & How is the assessment done? & An assessment of student perceptions \\
4 & How are the results presented? & A rating not a ranking \\
5 & What purpose does the rating serve? & Supporting school development and change \\
\hline
\end{tabular}

\subsection{What Is the Role of Business Schools? A Positive Impact Model for Assessing Business Schools}

The question about the role of business schools is a recurring topic that is being asked anew every few years. What we are seeing today is a move from economic impact to societal impact. Business schools are asked to embrace a larger role in society, in accordance with the changing and expanding role of business in society. In this they follow the changing demands on business. Additionally, they are asked to support business in making this move and to prepare students for the changing demands on their future tasks.

While established rankings assume that the only thing students care about and choose their business school for are salary and career opportunities, the PIR assumes that students are looking to create a positive impact through their work. It offers an alternative perspective to the traditional economic and selfish focus of rankings. It seeks to capture the societal impact of business schools and is based on an institutional focus by addressing the school, not a program. Its intention is to move business schools from becoming the best in the world, to becoming the best for the world [11,21].

In looking at the ranking criteria used by FT and ECON, they focus strongly on salary and career opportunities provided by the program and the school. It is not clear if there is a model behind the criteria used that explains the selection of criteria and would guide a further development. The PIR rating criteria are based on an explicit model capturing what positive impact of business schools means and how it has been operationalized. The PIR model consists of three areas, seven dimensions and 20 questions. The areas "educating" and "engaging" have been identified as critical roles for business schools in the $50+20$ vision for business schools [11]."Energizing" is an area that has been added to the $50+20$ model given its fundamental importance in orienting the school and its development. In each area there are two to three dimensions, explaining the scope and meaning of the area. Furthermore, each dimension is explained by two to four questions to assess the business school's current state and development to create a positive impact. As a result of the multistep design process the areas and dimensions of the PIR model were defined as shown in Table 3. The PIR is using the same rating scale for all questions, a ten-point rating scale ranging from $1=$ "I don't agree" to $10=$ "I completely agree" with no descriptors in between . 
Table 3. A Positive Impact Model for Assessing Business Schools.

\begin{tabular}{ccc}
\hline Area & Dimension & No. of Questions \\
\hline \multirow{2}{*}{ Energizing } & Governance & 2 questions \\
& Culture & 4 questions \\
Educating & Programs & 4 questions \\
& Learning Methods & 3 questions \\
Engaging & Student Support & 3 questions \\
& Institution as a Role Model & 2 questions \\
& Public Engagement & 2 questions \\
\hline
\end{tabular}

Area 1-Energizing: measures how governance and culture move the school ahead as perceived by its students. It is a lead indicator for a business school to increase its positive impact.

Governance dimension: Assessing the degree to which the school's vision includes societal engagement and to what degree sustainability and societal engagements are perceived as a driving force for the school.

Culture dimension: Assessing the degree to which a school is aligned with its purpose and vision and if change and innovation are a natural part of a school's culture. Assessing to what degree people in the school are motivated beyond self-interest and if the school supports personal development.

Area 2-Educating: measures a fundamental role of a business school by preparing students to become responsible leaders in business and society. It is an area of direct relevance to the students.

Programs dimension: Assessing the degree to which ethics, responsibility, and sustainability are integrated into study programs, and if societal stakeholders are typically a part of the student learning experience. Assessing if the study program develops skills to become a responsible leader and if program management listens to student suggestions for change.

Learning methods dimension: Assessing if the students are trained to apply methods and tools to societal challenges, and the degree to which they learn to co-create solutions with societal stakeholders. Assessing the degree to which teaching methods at the school are innovative.

Student support dimension: Assessing the degree to which students are supported by their schools to engage with business and societal stakeholders to create a positive impact in society. Assessing to what degree students at their school are supported to address societal challenges, and if they are encouraged to take into consideration the social and sustainable profile of companies in assessing employer attractiveness.

Area 3-Engaging: reflects the school's active engagement to earn the trust of students and society, but also its status as a respected public citizen.

Role Model dimension: Assessing if the school reports on its responsibility and sustainability goals and performance, and the degree to which the school's graduates are prepared to deal with sustainability challenges in their jobs.

Public Engagement dimension: Assessing the level of responsibility and sustainability engagement among the members of the school (faculty, staff, students), but also how the school's responsibility and sustainability engagement are recognized by the public.

The questions used to explain the different dimensions of the Positive Impact Model reflect the best available knowledge of the different stakeholder groups that created the model. These questions can and are expected to change over time as better questions or different aspects of the dimensions emerge. This will keep the model alive and up to date.

The results of the first edition of the PIR show the highest scores on the ten-point rating scale for the energizing area, with the culture dimension clearly leading (7.3), followed by the governance dimension (7.0). The students see their schools' culture as sensitized to address issues of social impact and sustainability and their schools' management as prepared to do so. The engaging area shows the lowest scores, with the school as role model dimension showing the lowest results (6.3) followed by the school's public engagement (6.5). So, while the schools seem to get ready at the top, as mirrored in the 
high values for culture and governance, their actual engagement is seen to be lagging. The educating area lies in the middle, with the programs dimension getting a slightly higher score (6.9) than the learning methods and the student engagement (both 6.8). Obviously, the transformation of the schools' teaching and learning practices does not yet live up to the students' expectations. The practical application to societal issues and engagements with stakeholders get a lower rating.

\subsection{Who Conducts the Assessment? A Rating by Students and for Students}

In traditional rankings the assessment is conducted by the concerned business schools: the schools provide the information, manage the rankings, and they are greatly interested in the rankings results and their marketing potential. The PIR is a rating "by students and for students." Students assess the school they know best and they care about most, their own school. The PIR thereby highlights quite deliberately one single stakeholder voice; a crucial and often ignored voice at schools. This is done in multiple ways.

Students are seen by the PIR as the main stakeholder of business schools. Both undergraduate and graduate students are at the center of the rating. Students are not only the main addressee of the PIR, but the rating is also working through students and student organizations to capture the student voice. While all other rankings work through the schools and their management to collect the data, PIR takes a new and different approach. The PIR 2020 worked with and through international student organizations, namely oikos International, Net Impact, AIESEC International, but also through national student organizations like Students organizing for Sustainability (SOS) in the UK and Studenten voor Morgen (Morgen) in the Netherlands, and through local student organizations at the different schools. They took over the task to distribute the survey to undergraduate and graduate students at their schools. As these student organizations are mainly active in the sustainability area, this has raised the question of selection bias. This may well be the case, although it is not obvious, if it results in a positive bias with students being overly positive about their schools' engagement, or if it results in a negative bias, with students being overly critical and expecting a stronger engagement by their schools. One of the participating schools has decided to do a controlled study of this question, based on their PIR 2020 data.

For data collection, the PIR provides an online tool to be used by the students to monitor the student survey returns. This tool can be used after the end of the data collection period to do further analyses of the data collected at their schools. PIR offers these results to the student body and the school management with the invitation to jointly identify opportunities for improvement. PIR thereby serves as a tool for impact-oriented school development, but also to empower the students to push the positive impact agenda at their schools.

The PIR assessment model is focusing on "educating" as a core function of business schools, rather than on other core functions like research or continuous education. It also includes the overarching areas "energizing" and "engaging." Teaching and education are certainly close to the heart of the students. They are also gravely underrepresented in established rankings. The PIR gives students the opportunity to use their experience and raise their voice for better integrating societal challenges in their studies and developing their skills to become a responsible leader.

In addition to the 20 closed questions addressed to the bachelor and master students, the PIR survey tool offers also open-ended questions on what the students want their schools to stop and start doing to increase their positive impact. In the first edition of the PIR the students provided an incredible wealth of constructive comments, as can be seen in Table 4 . 
Table 4. What the students in the PIR 2020 survey want their schools to stop and start doing.

\begin{tabular}{|c|c|}
\hline What Their Schools Should Stop Doing & What Their Schools Should Start Doing \\
\hline (1) Stop investing in fossil fuels & $\begin{array}{l}\text { (1) Make sustainability and social impact training } \\
\text { mandatory in curricula }\end{array}$ \\
\hline $\begin{array}{l}\text { (2) Stop treating sustainability and social entrepreneurship as } \\
\text { second-class topics }\end{array}$ & (2) Bring science and facts to the political debate \\
\hline $\begin{array}{l}\text { (3) Stop partnering with and accepting funds from unethical } \\
\text { companies and individuals }\end{array}$ & (3) Reduce $\mathrm{CO}_{2}$ emissions and food waste \\
\hline (4) Stop hiring professors who do not care about doing good & (4) Prioritize gender parity amongst students and faculty \\
\hline (5) Stop emphasizing profit maximization & $\begin{array}{l}\text { (5) Exchange more with other schools and faculties, share } \\
\text { good practice and evolve together }\end{array}$ \\
\hline $\begin{array}{l}\text { (6) Stop flying students abroad for a course just because it is } \\
\text { cool to do so }\end{array}$ & $\begin{array}{l}\text { (6) Rename the school to underline the social mission of } \\
\text { business education }\end{array}$ \\
\hline
\end{tabular}

The overall rating results reflect the positive impact of the business schools as judged by their own students. They provide comparative public information on business schools that will be of interest to other students. Many students care deeply about making a positive difference through their professional lives, yet they do not necessarily know how to find the right business school. This rating is not only a response to widespread demands for a positive impact of business schools, but it is a tool from today's students for the next generation of students and change agents who are looking for the best place to study.

\subsection{How Is the Assessment Done? An Assessment of Student Perceptions}

As an addition to and different from existing rankings, the PIR measures insights into business school reality and impact as constructed by one key stakeholder, their own students. The PIR rating thereby provides an alternative perspective based on student perceptions and experiences.

Why does the PIR use student perceptions? One reason is that perceptions define reality for the students and thereby influence their decisions. And the student perceptions reflected in the PIR results should be insightful and credible for prospective students looking for a business school of their choice.

Another reason is that the PIR taps into the student experience as a source of insight and knowledge. While established rankings are mostly based on quantitative information like the cost and value of an education, faculty-student ratio, or percentage of full-time faculty with a $\mathrm{PhD}$, they disregard qualitative information as subjective, even if it is of high relevance. The pedagogical approach, the learning atmosphere, the values and culture, and the commitment of the school and its faculty are extremely relevant for assessing the quality and impact of the school and its education. However, it is typically very complex, highly situational, and dependent on context. This is where student experiences and perceptions are not only insightful, but they cannot be replaced by quantitative information.

The PIR is working with an online assessment tool, which is based on the 20 closed questions from three areas and seven dimensions as developed in chapter 3.1. The PIR is using the same rating scale for all questions, a ten-point rating scale ranging from $1=$ "I don't agree" to $10=$ "I completely agree" with no descriptors in between. A 0 option of "I am not sure" was provided for every question as well, ensuring that students had the chance to opt out. The schools had to collect a minimum number of student responses, which was set at 30 valid responses in the pilot round. As the PIR should attract more business schools and students in the coming years, the minimum number of responses can and will be set higher. 3000 students completed the online survey. Local student organizations, contacted through the participating student associations, or student organizations and engaged students contacted through local sustainability offices or professors distributed the survey to fellow bachelor and master students.

So, how were the participating business schools selected for the PIR 2020? The top 50 business schools from the Financial Times Masters in Management (MiM) Ranking 2018 and the top 50 business schools from the Corporate Knights Green MBA Ranking 2018 were selected for the pilot round. In the spirit of openness and inclusiveness a few other schools were integrated, as they had expressed their interest in getting rated. Of the students at 97 schools contacted, students of 51 schools agreed to 
participate in the survey. Of all participating business schools 33 collected a sufficient number of responses to be rated ( 30 or more responses). Thirty schools were featured in the final rating. They were mainly from Europe and North America, but some also were from Asia and Central America [23]. The individual schools' rating results together with the complete rating reports were sent to the participating student organizations and the Deans' offices. They were invited and encouraged to use their data with the assessment tool for improving the positive impact of their schools. The Deans were invited to participate at the launch of the PIR results at the 2020 World Economic Forum at Davos.

\subsection{How Are the Results Presented? A Rating Not a Ranking}

Rankings position business schools in a highly differentiated league table, thereby pitting one school against the other. It creates a competition between different schools much like in a soccer or football league. Naturally, the participating schools will try everything to end up as leaders, thereby "beating" their competitors. At the same time rankings are being criticized for creating differences between schools which are too small to be meaningful. Therefore, and unfortunately, rankings discourage rather than support cooperative and collective action between schools. There is no reason to cooperate with a competitor. As a rating, the PIR follows a very different philosophy.

Ratings position schools in different categories. The PIR uses quintiles to position the schools according to their overall scores on five different levels and calls them beginning schools (level 1), emerging schools (level 2), progressing schools (level 3), transforming schools (level 4) and pioneering schools (level 5). Schools are listed alphabetically within each level, not in order of their performance, to further reduce a sense of competition. Moreover, PIR only publishes the schools in the top three quintiles (levels 3 to 5), purposefully reinforcing those that are successful in their transformation rather than shaming those who are not (yet) there.

Established rankings assess the schools relative to each other, with the best and poorest performing schools-among those schools participating-defining the range. The PIR rating compares all schools against an absolute ideal, a top rating in the eyes of their students, hence showing the potential for improvement even for leading schools. PIR is designed as a tool for improvement and transformation, giving the participating schools some protection, by classifying them into groups. It offers business schools a certain resilience to minor fluctuations, which can have grave consequences in the case of rankings.

PIR highlights the expectations of students towards their own schools. It is, indeed, their expectations that build the foundation of this rating and these voices are clear in their demand. They want business schools to contribute to a more sustainable world. The PIR hopes to foster learning and change processes both within and across business schools.

\subsection{What Purpose Does the Rating Serve? Supporting School Development and Change}

Established rankings have come to be used as a marketing tool for business schools, to address students, faculty, and participants of continuous education programs. They have become important tools for positioning the school on a national and international market. Business school programs or school quality are typical credence goods. A credence good is a type of good with qualities that cannot be observed and assessed by the consumer directly, making it difficult to evaluate its quality and value. Rankings have stepped in as highly welcome substitutes to communicate performance and quality in a credible way. The higher the reputation of the ranking, the better it is for the business school. The ranking value over time often becomes dissociated from what the ranking effectively measures and stands for. The more established a ranking is and the higher its reputation, the less the public tends to look at what it effectively measures and what these measures stand for. The PIR offers an alternative tool for business schools that care about being assessed in a way that is relevant for today's time and age.

In addition, the PIR has the potential to serve also as a tool for continually improving the business school. It reflects the positive impact of the school as seen and evaluated by their own students. 
This is done every year anew, with successive generations of students evaluating and reevaluating their schools. Learning and development is enabled through the design of the PIR. By providing the assessment tool to the student organizations and to school management both are empowered to use their data in many more productive ways. The involved international student organizations are also developing specific tools and approaches to put the school's data to creative use. In addition, the PIR organization is collecting and communicating best practices from the best performing schools in the rating. Through this, the PIR hopes to serve as an effective tool to catalyze system change in business schools and the whole business school landscape [24].

\section{Discussion}

The results of the first edition of the PIR, the PIR 2020, were presented at a side-event of the World Economic Forum (WEF) at Davos in January 2020. The presentation was embedded in a multi-stakeholder thought leader dialogue with a dozen deans from international business schools participating, together with representatives from ranking organizations, business, student organizations, and business school organizations. The discussions among the 50 participants were rich and fruitful. They are captured in a paper produced by Julia Christensen Hughes [22] on which these reflections draw.

A positive impact rating was very much welcomed at the Dean's multi-stakeholder dialogue. There was a strong feeling that the time had come for a positive impact approach and that there was great momentum in this. Changes and innovations about positive impact have been minimal at established rankings. They have been very slow and rather on the sidelines. The PIR was seen as an important addition to existing rankings, with a great potential for integration with other rankings.

The PIR's focus on teaching and students was seen by the participants to be as important as it is valuable because established rankings are not really covering this important perspective. Teaching and learning were seen to be gravely missing in established rankings. Moreover, giving students a voice was seen to be refreshing and disruptive. Creating a student platform around the PIR may become a powerful tool. Questions were raised regarding whether students have the insight and oversight to adequately assess their schools. Regarding teaching and education, the students were seen as highly competent and legitimized stakeholders to cast their votes. Regarding questions related to energizing and engaging their school, they clearly represent one important stakeholder, which has been neglected so far in rankings. Students are, however, only one stakeholder of business schools, and their perspectives will need to be balanced through the perspectives of other stakeholders.

Running the PIR through students and their organizations was seen to be very much in tune with new ways of grassroots organizing, bottom-up processes and the use of social media, typical for the new generation. For students, social media have replaced established communication channels like newspapers or magazines. Critically, it was asked if there was not a selection bias at play if the collection of responses was channeled through student organizations in the responsibility and sustainability space? Interestingly, there was no consensus on whether this bias was positive or negative. Lastly, the participants commented critically that perception was not the same as reality, which cannot be denied. The typical response to this criticism can be found in the Thomas theorem: "If people define situations as real, they are real in their consequences."

Furthermore, the form of a rating instead of a ranking was seen as very helpful to serve as a tool for school development and collaboration with other schools, not simply as a marketing tool to set one school apart from all other schools. Schools can learn from each other to improve on their positive impact. They must also collaborate to be able to contribute to long-run societal and planetary prosperity. To achieve the needed changes within business schools and beyond, it was critically mentioned that both drivers of change, collaboration, and competition would be needed. Collaboration will need to be balanced with competition to achieve the aspired outcomes.

Author Contributions: Both authors have contributed equally to this research. All authors have read and agreed to the published version of the manuscript. 
Funding: The PIR project received funding from Fundación VIVA Idea, San José, Costa Rica, and Mission Possible Foundation, Zug, Switzerland.

Conflicts of Interest: The authors are co-founders of the PIR and serve as members of the Supervisory Board (first author) and President of the PIR Association (second author).

\section{References}

1. Gioia, D.A.; Corley, K.G. Being Good Versus Looking Good: Business School Rankings and the Circean Transformation from Substance to Image. Acad. Manag. Learn. Educ. 2002, 1, 107-120. [CrossRef]

2. Peters, K. Business school rankings: Content and context. J. Manag. Dev. 2007, 26, 49-53. [CrossRef]

3. Adler, N.J.; Harzing, A.-W. When Knowledge Wins: Transcending the Sense and Nonsense of Academic Rankings. Acad. Manag. Learn. Educ. 2009, 8, 72-95. [CrossRef]

4. Pitt-Watson, D.; Quigley, E. Business School Rankings for the 21st Century. UN Principles for Responsible Management Education (PRME). January 2019. Available online: https://www.unprme.org/resource-docs/ 60555MBAREPORT0119pr03.pdf (accessed on 30 March 2020).

5. Byrne, J. MBA Rankings Largely 'Follow the Money'. Poets \& Quants, 7 September 2012.

6. Association of MBAs (AMBA). Are MBA Rankings Fit for Purpose? 2019. Available online: https://businessgraduatesassociation.com/wp-content/uploads/2019/06/Rankings-research-findingsmin.pdf (accessed on 30 March 2020).

7. Ortmans, L. A Ranking of Business School Rankings. 2018. Available online: https://www.linkedin.com/ pulse/ranking-business-school-rankings-laurent-ortmans/ (accessed on 30 March 2020).

8. Friedman, M. The social responsibility of business is to increase its profits. The New York Times Magazine, 13 September 1970.

9. Khurana, K. From Higher Aims to Hired Hands; Princeton University Press: Princeton, NJ, USA, 2007.

10. Jack, A. MBA students and employers demand 'profitable solutions for people and planet'. Business schools under pressure to place sustainability on a par with financial gain. Financial Times, 24 February 2020.

11. Muff, K.; Dyllick, T.; Drewell, M.; North, J.; Shrivastava, P.; Haertle, J. Management Education for the World. A Vision for Business Schools Serving People and Planet; Edward Elgar: Cheltenham, UK, 2013.

12. Dyllick, T. Responsible management education for a sustainable world. J. Manag. Dev. 2015, 34, 16-33. [CrossRef]

13. Tufano, P. A bolder vision for business schools. Harvard Business Review, 11 March 2020.

14. Network for Business Sustainability. 2002. Available online: https://www.nbs.net/ (accessed on 30 March 2020).

15. Network for Responsible Research in Business and Management. 2020. Available online: https://rrbm. network/ (accessed on 30 March 2020).

16. EFMD Quality Improvement System. EQUIS Standards and Criteria. 2019. Available online: https: //efmdglobal.org/accreditations/business-schools/equis/ (accessed on 30 March 2020).

17. AACSB. 2020 Guiding Principles and Standards for Business Accreditation. Effective 28 July 2020, p. 15. Available online: https://www.aacsb.edu/accreditation/standards/business (accessed on 18 August 2020).

18. Better World MBA Ranking 2019 (BWR). Corporate Knights. Available online: https://www.corporateknights. com/reports/2019-better-world-mba/ (accessed on 30 March 2020)

19. Times Higher Education University Impact Ranking. 2019. Available online: https: //www.timeshighereducation.com/rankings/impact/2019/overall\#!/page/0/length/25/sort_by/rank/sort_ order/asc/cols/undefined (accessed on 30 March 2020).

20. The Positive Impact Rating of Business Schools. Available online: https:/www.positiveimpactrating.org/ (accessed on 18 August 2020).

21. Muff, K.; Dyllick, T. Positive Impact Rating for Business Schools—Rating Report, 1st ed.; Positive Impact Rating Association: Lucerne, Switzerland, 2020; Available online: https://www.positiveimpactrating.org/ (accessed on 30 March 2020).

22. Christensen Hughes, J. Deans Multi-Stakeholder Dialogue at Davos: The Future of Business School Rankings and Ratings. PRME/Corporate Knights/Positive Impact Rating for Business Schools. 2020. Available online: https://d46c064f-971e-4554-b4f9-0441a70b5a46.usrfiles.com/ugd/d46c06_ bd36328275bb4f16aec9d0ca2b7f91a0.pdf (accessed on 9 April 2020). 
23. The Positive Impact Rating 2020 Edition. Available online: https://www.positiveimpactrating.org/copy-of2020-report (accessed on 26 October 2020).

24. The Positive Impact Rating 2021 Edition. Available online: https://www.positiveimpactrating.org/ (accessed on 26 October 2020).

Publisher's Note: MDPI stays neutral with regard to jurisdictional claims in published maps and institutional affiliations.

(C) 2020 by the authors. Licensee MDPI, Basel, Switzerland. This article is an open access article distributed under the terms and conditions of the Creative Commons Attribution (CC BY) license (http://creativecommons.org/licenses/by/4.0/). 